\title{
THE ROLE OF CEREBROSPINAL FLUID DYNAMICS USING PHASE-CONTRAST MAGNETIC RESONANCE IMAGING IN ASSESSMENT OF MULTIPLE SCLEROSIS ACTIVITY
}

\author{
By \\ Emad Mohamed Abd El-Hamid Abd El-Galil, Mostafa Mohamed \\ Mostafa Shakweer and Ahmed Yahia Ahmed Ashour \\ Department of Radiodiagnosis, Faculty of Medicine, Al-Azhar University, (Damietta) \\ Corresponding author: Emad Mohamed Abd El-Hamid, \\ E-mail: emadelmasry1711@gmail.com
}

\begin{abstract}
Background: Multiple sclerosis (MS) is a chronic complex neurodegenerative disease, targeting the central nervous system (CNS) and widely believed to be autoimmune in nature. Alterations to the normal flow of Cerebrospinal fluid (CSF) in the brain could be a contributing factor to the accumulation of toxic substances in the brain interstitium and may be related to the pathogenesis of neurological disorders such as Alzheimer's disease and MS.
\end{abstract}

Objective: To evaluate the CSF dynamics and its relation to MS activity using phase-contrast magnetic resonance imaging (PC-MRI).

Patients and methods: This prospective study was performed between April 2020 and October 2020. A total of 45 cases were enrolled in this study divided into three equal groups: MS patients with active plaquesenhanced on MRI (group 1), MS patients with chronic plaques (group 2), and healthy controls (group 3). Quantitatively evaluation of the CSF flow was performed at the level of the cerebral aqueduct by PC-MRI.

Results: Regarding to peak velocity, average velocity, net volume and average flow, there were no statistically significant differences between the three studied groups. Regarding to forward volume, reverse volume and aqueductal area, there were statistically significant differences between the three studied groups.

Conclusion: The forward and reverse CSF flow volumes and aqueductal area were significantly higher in the MS patients. These findings may support the venous theory in MS patients, but may also be explained by atrophy-dependent ventricular dilatation independent of the venous theory in MS patients.

Keywords: Cerebrospinal Fluid Dynamics, Phase-Contrast, Magnetic Resonance Imaging, Multiple Sclerosis Activity.

\section{INTRODUCTION}

MS is an inflammatory disease characterized by demyelination centered on the cerebral veins in the white matter (Filippi et al., 2019).

The normal CSF circulation depends on the proper balance between CSF ultrafiltration (from lateral ventricular veins) and venous system clearance from CSF opening at the level of dural sinuses (Öner et al., 2018).

Chronic cerebro-spinal venous insufficiency (CCSVI) has been suggested as a new hypothesis for the pathogenesis of MS disease. CCSVI-related MS 
hypothesis suggests that significant decrease in CSF flow occurs through cerebral aqueducts secondary to impaired venous outflow from the CNS (Zamboni et al., 2012). The subject of CCSVI has been mired in controversy, with many researchers doubting that it is indicative of any pathology (Beggs et al., 2014). However, there is a growing evidence that restricted cerebral venous outflow is a phenomenon that is more prevalent in patients with MS, even though it is also observed in both healthy individuals and those with other neurological disease (Baracchini et al., 2013).

A great number of demyelinating plaques of different sizes with sharp borders and round, oval or irregular shapes can be seen in MS (Öner et al., 2018).

MRI can support the clinical information for MS diagnosis, allowing an earlier and accurate diagnosis and, consequently, earlier treatment (Filippi et al., 2016).

CSF is predominantly produced by the choroid plexuses of the lateral, third, and fourth ventricles. CSF is eventually cleared to the venous system through arachnoid villi, to the cervical lymphatics through the cribriform plate, and to the recently discovered meningeal lymphatics that line the dural sinuses. Alterations to the normal flow of CSF in the brain could be a contributing factor to the accumulation of toxic substances in the brain interstitium and may be related to the pathogenesis of neurological disorders such as Alzheimer's disease and MS. (Schubert et al., 2019).

PC-MRI is a non-invasive technique that can be used to quantitatively evaluate
CSF flow dynamics (Korbecki et al., 2019).

The aim of this study was to evaluate the CSF dynamics and its relation to MS activity using PC-MRI.

\section{PATIENTS AND METHODS}

This prospective study was performed between April 2020 and October 2020 at the Radiodiagnosis Department, New Damietta Hospital, Al-Azhar University and other private center using 1.5 tesla $(\mathrm{T})$ magnetic resonance scanners (Philips Achieva, Netherland and Siemens MGNETOM, Aera respectively).

Inclusion criteria: Age: from 20 to 50 years and no gender predilection. The selection of subjects was done after prior explanation of the aim of the study, and free well-written approval consent was taken. The whole work was done according to the ethical committee, Faculty of Medicine, Al-Azhar University.

Exclusion criteria: Patients who had cardiac pacemaker, metallic foreign body in their eye, aneurysm clip in brain, any electrically or magnetically activated implants (cochlear implants), severe claustrophobia, excessive motion and uncooperative, bad general condition and contra-indications for the contrast medium, e.g. severe allergic reaction or renal impairment.

A total of 45 cases were enrolled in this study, divided into three equal groups (11 females and 4 males each). Their ages ranged from 20 to 50 years. They were referred from the outpatient clinic of the Neurology Department, Al-Azhar Faculty of Medicine. 
- Group (1): Patients were referred from neurology department as Relapsingremitting multiple sclerosis (RRMS) and had active plaques on MRI.

- Group (2): Patients were referred from neurology department as RRMS and had chronic plaques on MRI.

- Group (3) or control group: Subjects were free from any medical or neurological disease and had normal conventional MRI.

\section{All patients involved in this study were subjected to:}

1. Full medical history including: name, age, complaint of the patients, duration of the complaint, history of any disease, previous operations, and any previous radiological examination.

2. Clinical examination (by referring doctor).

3. Laboratory investigations (e.g. serum creatinine).

4. Conventional MRI using routine sequences for brain study and Postcontrast T1-weighted study (in MS cases).

\section{PC-MRI.}

Patient preparation and positioning: Patients needed no specific preparation and imaging was carried out with patient in supine position, using standard head coil.

Conventional MRI: Axial T1-weighted, T2-weighted and fluid-attenuated inversion recovery (FLAIR) and sagittal FLAIR. Post-contrast axial T1-weighted study (in MS cases) was done after injection of gadopentate dimeglumine $(0.1$ $\mathrm{ml} / \mathrm{Kg}$ ). Axial T1-weighted (repetition time / echo time (TR/TE): 500-600/16ms), fast spin-echo axial T2-weighted (TR/TE: 4490/86ms), axial \& sagittal fast FLAIR (TR/TE /TI: 9000/ 14 /2500ms). The slice thickness was $5 \mathrm{~mm}$ in axial and $3 \mathrm{~mm}$ in sagittal, matrix size was $128 \times 256$ \& the field of view (FOV) was 220-240 mm.

Phase contrast MRI Protocol: For axial phase contrast images the following parameters were used: TR ranged from 12 to $17 \mathrm{~ms}$, TE ranged from 7.3 to $10.4 \mathrm{~ms}$, Flip angle $=15^{\circ}$, Matrix 256x256 pixels and Slice thickness $=5 \mathrm{~mm}$.

First step was the cardiac gating. It was performed with MR compatible peripheral pulse transducer applied to the subject's finger. Velocity encoding (VENC) was adjusted for each group, the mean VENC value is $5-8 \mathrm{~cm} / \mathrm{sec}$ for standard CSF flow imaging. Lower VENC values $(2-4 \mathrm{~cm} / \mathrm{sec})$ can be helpful in patients with brain atrophy. Higher VENC values $(20-25 \mathrm{~cm} / \mathrm{sec})$ for hyper-dynamic flow, the velocity direction was encoding in the cranio-caudal direction.

In mid-sagittal image, a localizer was placed perpendicular to the aqueduct of sylvius, the localizer should pass through the aqueduct in the axial plane. Phase contrast images were obtained in one cardiac cycle. A series of phase and magnitude images at different cardiac phases were obtained.

After the data acquisition, all images were transferred to the workstation equipment with $\mathrm{Q}$ flow software (on Philips scanner) and Argus flow software (on Siemens scanner). A ROI (region of interest) drawn manually to include all pixels that reflected the CSF flow signals on the phase images after magnification of the images to clarify the flow, after that 
the CSF flow parameters were automatically extracted.

\section{Data analysis:}

Quantitative analysis: Peak systolic and diastolic velocities were extracted from the mean velocity-time curve. In this curve the area above the baseline represented the diastolic flow with its highest point is the $\mathrm{PDV}$ in $\mathrm{cm} / \mathrm{sec}$, the area under the baseline represented the systolic velocity with the furthest point from the baseline represented the PSV in $\mathrm{cm} / \mathrm{sec}$. Mean velocity $(\mathrm{cm} / \mathrm{sec})$ referred to the mean CSF flow velocity. Mean flux $(\mathrm{ml} / \mathrm{sec})$ which is the mean CSF flow volume per second. Forward flow volume (ml) that represented the CSF flow volume in the encoding direction, while backward flow volume $(\mathrm{ml})$ represented CSF flow volume moving in the opposite direction and the net volume $(\mathrm{ml})$ is the difference between both. The aqueduct area was represented by the ROI area (cm2) (figure 1).

Statistical analysis of the data: Data were tabulated, coded then analyzed using the computer program SPSS (Statistical package for the social sciences) version 17.0 to obtain:
Descriptive data: Descriptive statistics were calculated in the form of mean + standard deviation (SD), range (minimummaximum) \& frequency (numberpercent).

\section{Analytical statistics:}

- Shapiro-Wilk test was applied as a test of normality.

- In the statistical comparison between the different groups, the significance of difference was tested using one of the following tests:

1. Student's t-test (Unpaired): Used to compare between mean of two different groups of numerical (parametric) data.

2. Mann-whitney $U$ test: Used to compare between two different groups of numerical (nonparametric) data.

3. Kruskal-Wallis test: Used to compare between more than two related groups of numerical (nonparametric) data.

$\mathrm{P}$ value $<0.05$ was considered statistically significant. 


\section{RESULTS}

Regarding to age and gender, there were no statistically significant differences between the three studied groups. Regarding to duration of the disease, there was a statistically significant difference between the studied groups (Table 1).

Table (1): Demographic data of MS patients \& control subjects and comparison between MS patients as regard duration of the disease

\begin{tabular}{|c|c|c|c|c|}
\hline \multicolumn{2}{|c|}{$\begin{array}{l}\text { Groups } \\
\text { Parameters }\end{array}$} & $\begin{array}{c}\text { Group (I) } \\
(\mathbf{N}=15)\end{array}$ & $\begin{array}{c}\text { Group (II) } \\
(\mathbf{N}=15)\end{array}$ & $\begin{array}{c}\text { Control } \\
(\mathrm{N}=15) \\
\end{array}$ \\
\hline \multicolumn{2}{|c|}{ Age (years) } & $21-50$ & $20-50$ & $20-49$ \\
\hline \multicolumn{2}{|c|}{ Mean \pm SD } & $33.9+9.99$ & $33.70 \pm 9.40$ & $33.80 \pm 7.91$ \\
\hline \multirow{2}{*}{ Sex } & Male & $4(26.66 \%)$ & $4(26.66 \%)$ & $4(26.66 \%)$ \\
\hline & Female & $11(73.33 \%)$ & $11(73.33 \%)$ & $11(73.33 \%)$ \\
\hline \multicolumn{2}{|c|}{$\begin{array}{l}\text { Duration of the } \\
\text { disease: } \\
\text { Mean } \pm S D\end{array}$} & $3.33 \pm 2.28$ & $7.00 \pm 3.36$ & $(1,-\infty)$ \\
\hline \multicolumn{2}{|c|}{ P. Value } & \multicolumn{2}{|c|}{0.006} & \\
\hline
\end{tabular}

Regarding to peak velocity, average velocity, net volume and average flow, there were no statistically significant differences between the three studied groups.
Regarding to forward volume, reverse volume and aqueductal area there were statistically significant differences between the three studied groups (Table 2).

Table (2): CSF Dynamics in RRMS Patients and Controls.

\begin{tabular}{|c|c|c|c|c|}
\hline \multirow[b]{2}{*}{ Parameters } & $\begin{array}{l}\text { MS patients with } \\
\text { active plaques }\end{array}$ & $\begin{array}{c}\text { MS patients } \\
\text { with chronic } \\
\text { plaques }\end{array}$ & Controls & \multirow[t]{2}{*}{ p -value } \\
\hline & $\begin{array}{c}\text { Mean } \pm \text { SD } \\
\text { (range) }\end{array}$ & $\begin{array}{c}\text { Mean } \pm \text { SD } \\
\text { (range) }\end{array}$ & $\begin{array}{l}\text { Mean } \pm \text { SD } \\
\text { (range) }\end{array}$ & \\
\hline $\begin{array}{l}\text { Peak velocity } \\
(\mathrm{cm} / \mathrm{sec})\end{array}$ & $\begin{array}{l}5.84+1.17 \\
(2.7-6.40)\end{array}$ & $\begin{array}{l}5.76+1.35 \\
(3.40-8.4)\end{array}$ & $\begin{array}{l}4.59+1.53 \\
(2.9-7.80)\end{array}$ & 0.056 \\
\hline $\begin{array}{l}\text { Average } \\
\text { velocity } \\
(\mathrm{cm} / \mathrm{sec})\end{array}$ & $\begin{array}{l}0.52 \pm 0.33 \\
(0.08-1.13)\end{array}$ & $\begin{array}{l}0.31 \pm 0.20 \\
(0.03-0.70)\end{array}$ & $\begin{array}{l}0.41 \pm 0.29 \\
(0.05-1.07)\end{array}$ & 0.143 \\
\hline $\begin{array}{c}\text { Forward } \\
\text { volume }(\mathrm{ml})\end{array}$ & $\begin{array}{c}0.029 \pm 0.013 \\
(0.01-0.06)\end{array}$ & $\begin{array}{c}0.039 \pm 0.020 \\
(0.01-0.08)\end{array}$ & $\begin{array}{l}0.02 \pm 0.01 \\
(0.01-0.04)\end{array}$ & $0.036 *$ \\
\hline $\begin{array}{l}\text { Reverse } \\
\text { volume } \\
(\mathrm{ml})\end{array}$ & $\begin{array}{c}0.024 \pm 0.016 \\
(0.00-0.05)\end{array}$ & $\begin{array}{c}0.029 \pm 0.0183 \\
(0.01-0.07)\end{array}$ & $\begin{array}{l}0.01 \pm 0.011 \\
(0.00-0.030)\end{array}$ & $0.007 *$ \\
\hline $\begin{array}{l}\text { Net forward } \\
\text { volume }(\mathrm{ml})\end{array}$ & $\begin{array}{l}0.027 \pm 0.07 \\
(0.00-0.03)\end{array}$ & $\begin{array}{c}0.014 \pm 0.012 \\
(0.00-0.04)\end{array}$ & $\begin{array}{c}0.009 \pm 0.007 \\
(0.00-0.02)\end{array}$ & 0.559 \\
\hline $\begin{array}{l}\text { Average flow } \\
(\mathrm{ml} / \mathrm{sec})\end{array}$ & $\begin{array}{c}0.01 \pm 0.0136 \\
(0.00-0.04)\end{array}$ & $\begin{array}{c}0.015 \pm 0.0139 \\
(0.00-0.04)\end{array}$ & $\begin{array}{c}0.013 \pm 0.026 \\
(0.00-0.04)\end{array}$ & 0.272 \\
\hline $\begin{array}{l}\text { Aqueductal } \\
\text { area }(\mathbf{m m} 2)\end{array}$ & $\begin{array}{c}4.38 \pm 1.66 \\
1.60-7.40\end{array}$ & $\begin{array}{l}5.7 \pm 1.88 \\
2.90-9.00\end{array}$ & $\begin{array}{l}3.17 \pm 1.9 \\
1.30-5.20\end{array}$ & $0.000 *$ \\
\hline
\end{tabular}




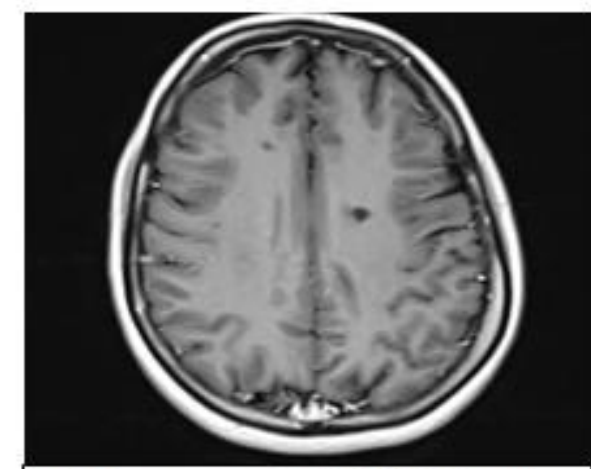

A) Post-contrast axial T1WI showing non contrast-enhancing plaque in periventricular white matter.

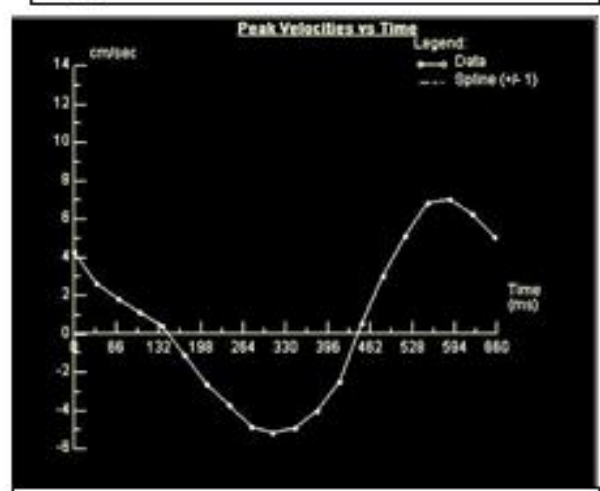

C) Peak velocity - time curve.

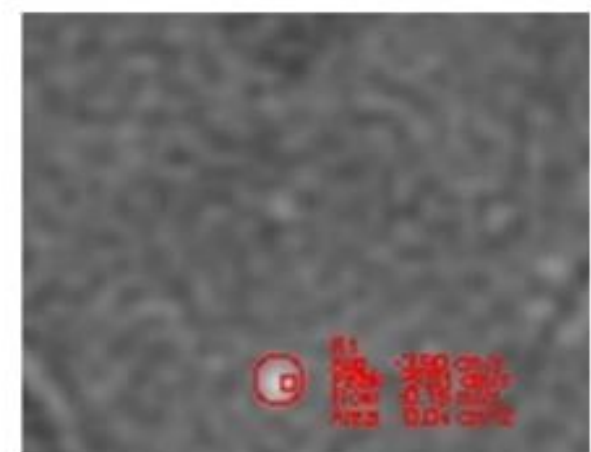

B) ROI placement to cover the whole cerebral aqueduct.

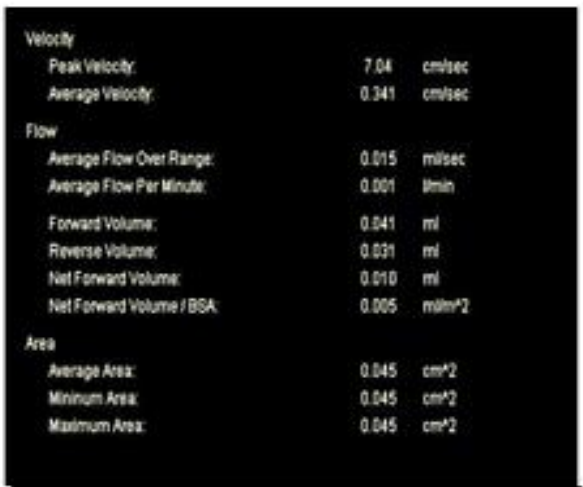

D) Summary showing CSF flow parameters.

Figure (1): A-D, a case of RRMS with chronic plaques.

\section{DISCUSSION}

PC-MRI facilitates accurate and noninvasive evaluation of the flow direction and flow rate of intracranial blood and CSF (Korbecki et al., 2019).

Zamboni et al. (2012) reported a strong relationship between CCSVI and MS. They found a significantly higher prevalence of CCSVI in MS patients, as compared to controls, and consequently, a decrease in net CSF flow (mL/beat) passing through the cerebral aqueduct. They concluded that CCSVI has a marked effect especially on intracranial fluid balance in the pathophysiology of brain.

Sundström et al. (2010) performed a study to test the hypothesis of CCSVI and, unlike Zamboni et al. (2012), did not detect any difference in internal jugular venous outflow and aqueductal CSF flow between RRMS patients and the control group.

MS patients were divided into 2 groups according to the condition of plaques that were detected on MRI: MS patients with active plaques who exhibit contrast enhancement and those with chronic disease non-enhancement. Therefore, we determined whether PC-MRI contributes to differential diagnosis of active and chronic disease in MS.

If CSF flow is decreased due to impaired extra-cranial venous drainage in MS patients, based on the study of Zamboni et al. (2012), we expected lower 
CSF flow values in the intense period of active inflammation.

In our results, there were no statistical differences in age and sex between the three studied groups. Likewise, various studies have reported an increase in CSF flow dynamics due to aging (Sartoretti et al., 2019).

Our study compared flow speeds in addition to CSF flow volumes passing from the cerebral aqueduct in MS patients. No significant differences were found in terms of peak velocity, average velocity, net CSF flow volume and average flow.

Cranio-caudal (forward) and caudocranial (reverse) CSF flow volumes (ml) and aqueductal area were higher in the MS patients with chronic plaques, as compared to patients with active plaques; and of these parameters, reverse volume was statistically significant. In addition, these parameters were higher in MS patients, as compared with the control group.

Increased cranio-caudal and caudocranial CSF flow volume and aqueductal area in MS patients could possibly be due to cerebral atrophic changes that may occur at every stage of MS. CSF spaces expand with cerebral atrophy and consequently, CSF flow volumes in a cardiac cycle pass through the cerebral aqueduct.

This idea is supported by Chiang et al. (2010) who found a relationship between ventricular morphology and aqueductal CSF flow in healthy subjects and in patients with communicating hydrocephalus. They concluded that aqueductal CSF flow should not be regarded independently of ventricular morphology.

Zamboni et al. (2012) suggested that impaired CSF dynamics in MS patients contributes to an increase in volumes of the third and lateral ventricles. In addition, reverse volume in the definitive diagnosis of active and chronic period MS disease, was higher in MS patients with chronic plaques. This result can be used in the place of contrast-enhanced MRI.

Increased cranio-caudal and caudocranial CSF flow volume $(\mathrm{ml})$ in $\mathrm{MS}$ patients can be explained by the venous hemodynamic impairment in MS patients mentioned by Zamboni et al. (2012). Although we did not investigate this phenomenon in our study, we suggest that it causes a mild deficit in CSF reabsorption through the sinuses and an increase in the above parameters. Another finding supports this hypothesis: the CSF regurgitant fraction was found to be slightly higher in the MS patients than the control group; however, this difference was not statistically significant

Gorucu et al. (2011) reported that the net CSF flow volume showed no significant differences between MS patients and controls. In the present study, the net CSF flow volume (ml) and average flow $(\mathrm{ml} / \mathrm{sec})$ parameters evaluated with PC-MRI, were not found to be statistically significant between MS patients and the control group.

Although cranio-caudal (ml) and caudo-cranial CSF flow volume $(\mathrm{ml})$, and aqueductal area (mm2) were higher in MS patients, the fact that peak systolic and diastolic velocities were not significantly different between MS patients and controls may be seen as controversial. But 
peak systolic or peak diastolic velocities $(\mathrm{cm} / \mathrm{s})$ are not the only parameters used in calculation of CSF flow volume (ml) (Oner et al., 2017).

This study is not without limitations: First the number of the enrolled individuals was relatively small and, therefore, further studies should extend our findings using a larger sample size. Also, we did not evaluate the venous outflow abnormalities and the ventricle volumes, which is a limitation of our study. In addition, PC-MRI may result in errors in quantitative measurements, due to non-linear gradients, partial volume effects, and errors in placing ROI (Demirtaş et al., 2020).

Lastly, the effect of altered CSF pulsatility on long term neurologic outcomes is unknown, and only longitudinal studies will be able to provide further insight on this important question.

\section{CONCLUSION}

The forward and reverse CSF flow volumes and aqueductal area were significantly higher in the MS patients. The altered cerebral flow physiology may be used to differentiate active versus chronic disease. These findings may support the venous theory in MS patients, but may also be explained by atrophydependent ventricular dilatation independent of the venous theory in MS patients.

\section{REFERENCES}

1. Baracchini $C$, Atzori $M$ and Gallo $P$. (2013): CCSVI and MS: no meaning, no fact. Neurol Sci., 34(3): 269-79.

2. Beggs CB, Magnano C, Shepherd SJ, Marr K, Valnarov V, Hojnacki D, Bergsland N, Belov P, Grisafi S, Dwyer
MG, Carl E, Weinstock-Guttman B and Zivadinov R. (2014): Aqueductal cerebrospinal fluid pulsatility in healthy individuals is affected by impaired cerebral venous outflow. J Magn Reson Imaging, 40(5): 1215-22.

3. Chiang WW, Takoudis CG, Lee SH, Weis-McNulty A, Glick $R$ and Alperin N. (2010): Relationship between ventricular morphology and aqueductal cerebrospinal fluid flow in healthy and communicating hydrocephalus. Investigative Radiology, 44(4): 192-199.

4. Demirtaş G, Siğirci A, Öztürk $M$ and Güngör S. (2020): Is cerebral spinal fluid flow associated with body mass index and head circumference in healthy children?. A phase contrast magnetic resonance imaging study. Egypt J Radiol Nucl Med., 51: 107111.

5. Filippi M, Preziosa P, Banwell BL, Barkhof F, Ciccarelli O, De Stefano N, Geurts JJG, Paul F, Reich DS, Toosy AT, Traboulsee A, Wattjes MP, Yousry TA, Gass A, Lubetzki C, Weinshenker BG and Rocca MA. (2019): Assessment of lesions on magnetic resonance imaging in multiple sclerosis: practical guidelines. Brain, 142(7): 1858-1875.

6. Filippi M, Rocca MA, Ciccarelli O, De Stefano N, Evangelou N, Kappos L, Rovira A, Sastre-Garriga J, Tintorè M, Frederiksen JL, Gasperini C, Palace J, Reich DS, Banwell B, Montalban $X$ and Barkhof F. (2016): MRI criteria for the diagnosis of multiple sclerosis: MAGNIMS consensus guidelines. Lancet Neurol., 15(3): 292-303.

7. Gorucu Y, Albayram S, Balci B and Hasiloglu Z (2011): Cerebrospinal fluid flow dynamics in patients with multiple sclerosis: a phase contrast magnetic resonance study. Funct Neurol., 26(4): 215-222. 
8. Korbecki A, Zimny A and Podgórski P. (2019): Imaging of cerebrospinal fluid flow: fundamentals, techniques, and clinical applications of phase-contrast magnetic resonance imaging. Pol J Radiol., 84: 240-250.

9. Öner S, Kahraman AS, Özcan C, Özdemir ZM, Ünlü $S$, Kamışlı Ö and Öner Z. (2018): Cerebrospinal Fluid Dynamics in Patients with Multiple Sclerosis: The Role of Phase-Contrast MRI in the Differential Diagnosis of Active and Chronic Disease. KJR., 19(1): 72-78.

10.Oner Z, Sagir KA, Kose E, Kavakli A, Cay $M$ and Ozbag D. (2017): Quantitative Evaluation of Normal Aqueductal Cerebrospinal Fluid Flow Using Phase-Contrast Cine MRI According to Age and Sex. Anat Rec (Hoboken), 300: 549-555.

11.Sartoretti T, Wyss M, Sartoretti E, Arash N and Sabine S. (2019): Sex and Age Dependencies of Aqueductal Cerebrospinal Fluid Dynamics Parameters in Healthy Subjects. Front Aging Neurosci., 11: 199-204.
12.Schubert JJ, Veronese M, Marchitelli L, Bodini B, Tonietto M, Stankoff B, Brooks DJ, Bertoldo A, Edison $P$ and Turkheimer F. (2019): Dynamic 11C-PIB PET shows cerebrospinal fluid flow alterations in Alzheimer disease and multiple sclerosis. J Nucl Med., 60(10): 1452-1460.

13.Sundström P, Wåhlin A, Ambarki K, Birgander R, Eklund $A$ and Malm J. (2010): Venous and cerebrospinal fluid flow in multiple sclerosis: a case-control study. Annals of Neurology, 68(2): 255259.

\section{Zamboni $P$, Menegatti E, Conforti $P$ and} Shepherd S. (2012): Assessment of cerebral venous return by a novel plethysmography method. Journal of Vascular Surgery, 56(3): 677-85. 
دور ديناميكيات السائل النخاعى باستخدام التصوير بالتباين

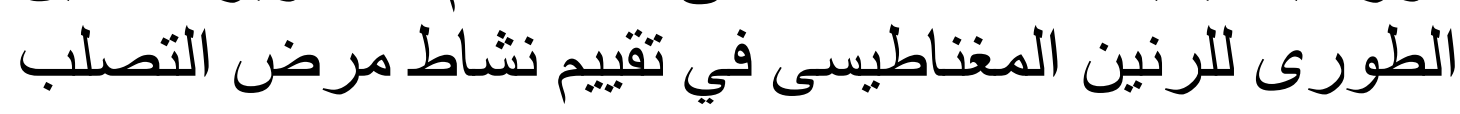

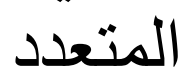

عماد محمد عبد الحميد عبد الجليل، مصطفي محمد مصطفي شقوير، أحمد يحيى أحمد عاثور

قسم الأثعة التثخيصية, كلية الطب, جامعة الأزهر (دمياط)

E-mail: emadelmasry1711@gmail.com

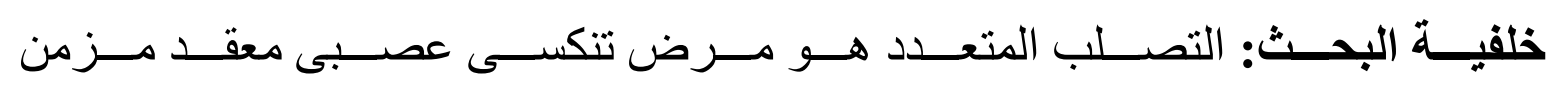

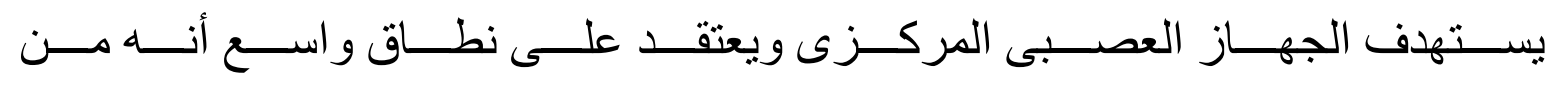

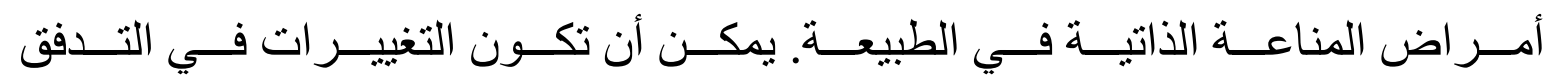

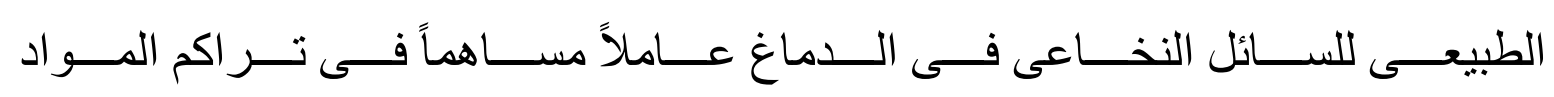

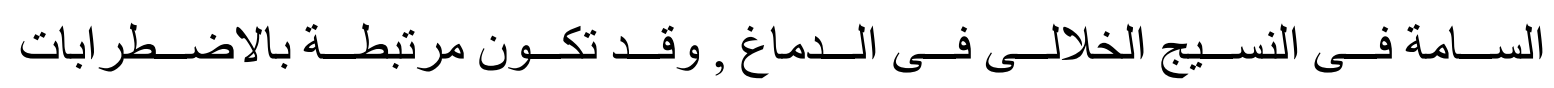
العصبية مثل مرض الزهايمر و التصلب المتعدد.

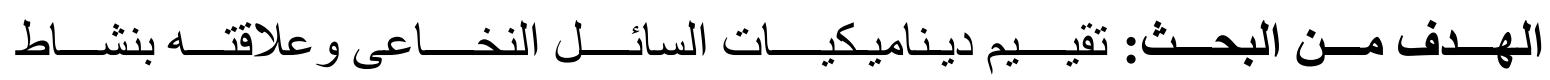

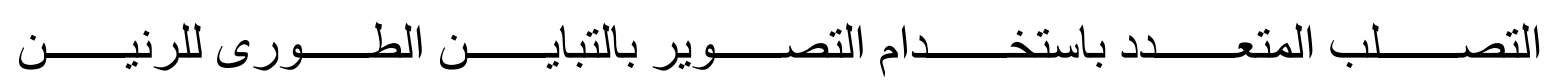

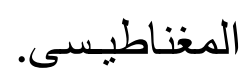

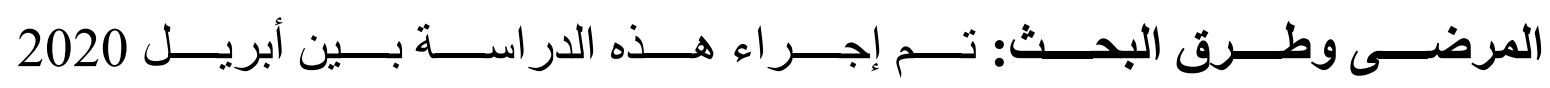

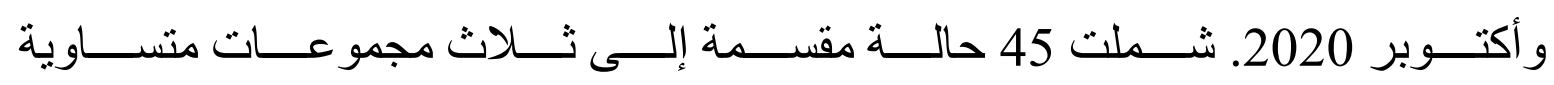

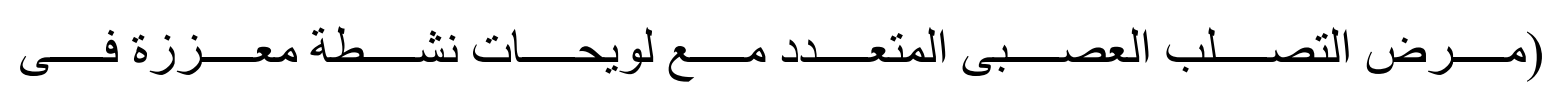

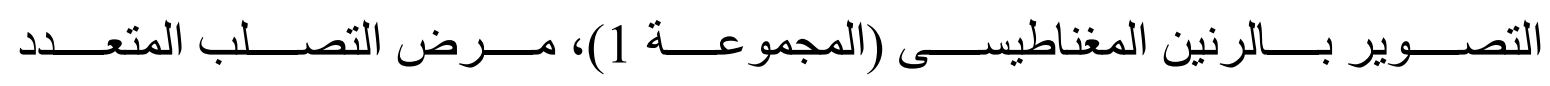

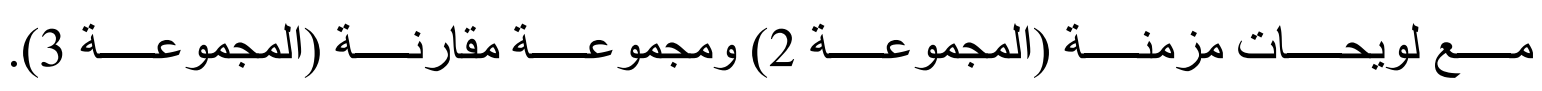

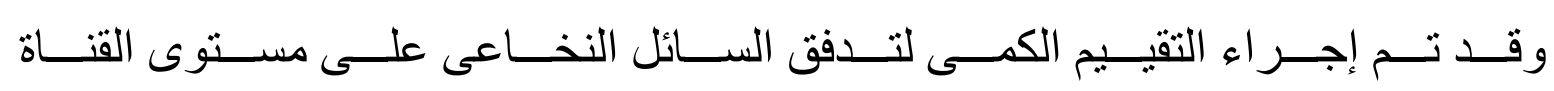
الدماغية بواسطة التصـوير بالتبايـن الطورى للرنين المغناطيسى. 


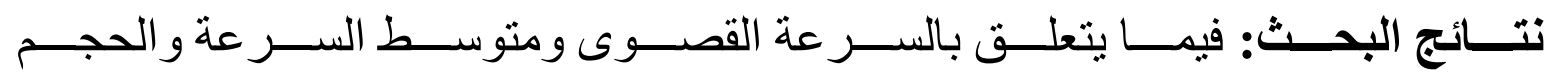

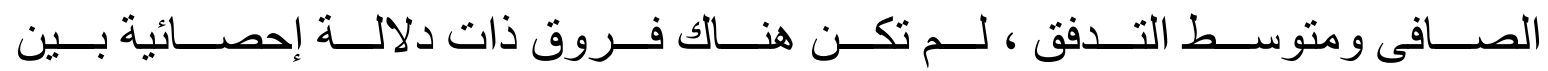

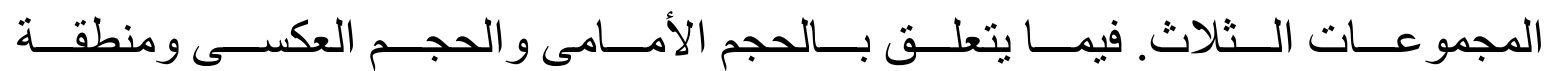
القناة كانت هناك فروقاً ذات دلالة إحصائية بين المجمو عات الثناث.

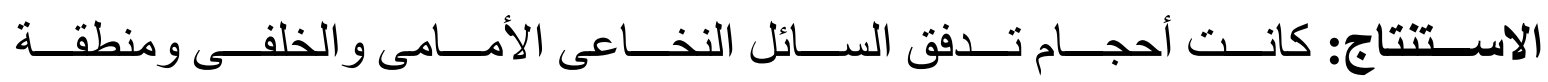

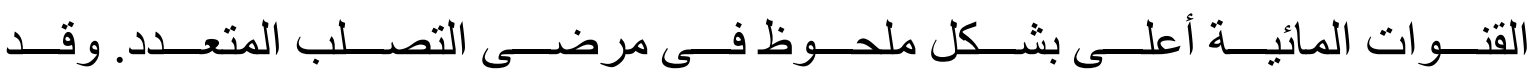

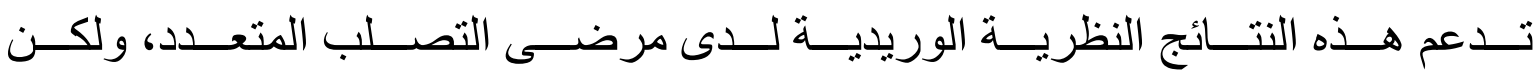

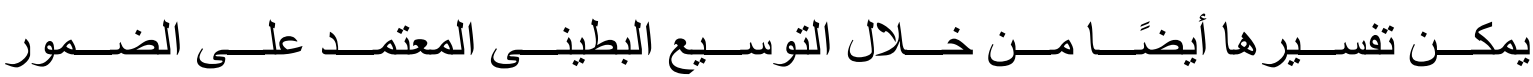
المستقل عن النظرية الوريدية فى مرضى التصلب المتعدد.

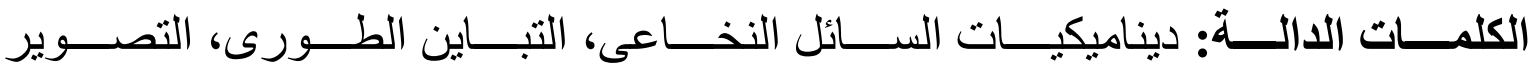
بالرنين المغناطيسى، نشاط مرض التصلب المتعدد. 